\title{
Defining high-resolution dredge fishing grounds with Automatic Identification System (AIS) data
}

\author{
Damien Le Guyader ${ }^{1, *}$, Cyril Ray ${ }^{2}$, Françoise Gourmelon ${ }^{1}$ and David Brosset ${ }^{2}$ \\ ${ }^{1}$ CNRS LETG-Brest, European Institute for Marine Studies, University of Western Brittany, Plouzané 29280, France \\ 2 Naval Academy Research Institute, Lanvéoc 29240, France
}

Received 4 January 2017 / Accepted 10 April 2017

Handling Editor: Verena Trenkel

\begin{abstract}
High resolution estimates of bottom towed fishing gears are needed to provide relevant information for natural resource management, impact assessment and maritime spatial planning. The use of satellite-based vessel monitoring system (VMS) data is constrained by data access restrictions as well as rather coarse data resolution. This study focuses on mapping dredge gear fishing grounds using fishing effort estimates at the métier level based on automatic identification system (AIS) data. The performance of the approach was evaluated in terms of correct discrimination between fishing and non-fishing activities for known fishing positions as well as appropriate error propagation. The test was conducted in the Bay of Brest (France) in partnership with a committee of local fishers. The results identified dredge fishing grounds for great scallop (Pecten maximus) in the western part of the Bay of Brest and provided highresolution information for scientists and local decision makers on the spatial and temporal seasonal variability of fishing effort. The proposed method is semi-automatic and generic making it suitable for other applications.
\end{abstract}

Keywords: dredge fishery / fishing activity / trajectories / spatio-temporal analysis / automatic identification system / métier analyses

\section{Introduction}

Estimates of the spatial distribution and intensity of fishing activities are necessary to provide relevant information for natural resources management, impact assessment (Boulcott et al., 2014) and maritime spatial planning (Tidd et al., 2014). There is a need for a multi-scale approach (Dunn et al., 2016), while access to high-resolution information is challenging, especially for small-scale fisheries (Breen et al., 2015; Gloaguen et al., 2016). Since the European Union (EU) introduced the Vessel Monitoring System (VMS) (EC, 2002), significant progress had been made regarding the use of this data for deriving fishing effort estimates (Piet et al., 2007; Lee et al., 2010; Hintzen et al., 2012; Russo et al., 2014; Tidd et al., 2014). However, VMS data have certain limitations. Small vessels $(<12 \mathrm{~m})$ are not equipped, and VMS data analyses are usually conducted at a spatial resolutions ranging from 1 to $10 \mathrm{~km}$ because of the low reporting frequency. In addition due to confidentiality and commercial sensitivity, access to raw VMS data is restricted (Lee et al., 2010), which

\footnotetext{
*e-mail: d.le.guyader@gmail.com
}

hampers the use of VMS data based studies and publications (Hinz et al., 2013).

In recent years, the Automatic Identification System (AIS), which was initially intended to improve ship safety and transmits at high frequencies, has provided a valuable source of information for analysing spatial and temporal distributions of human activities at multiple scales (Shelmerdine, 2015). The AIS has been mandated by the International Maritime Organization (IMO) through the Safety of Life at Sea Convention (SOLAS) since 2002. The archived AIS data are relatively easy to access, which, combined with the growing worldwide coverage (HØye et al., 2008), has recently opened research opportunities for mapping fishing activities at global (de Souza et al., 2016), European (Natale et al., 2015; Vespe et al., 2016) and regional scales (McCauley et al., 2016). All these studies described fishing activity by gear type.

Regardless of the data source (VMS or AIS), estimation of the spatial distribution and fishing intensity of commercial fishing generally follows four methodological steps: enrich data with qualitative information on the type of fishing activity (specifying gear type or métier), infer whether a ship is engaged in fishing activity, identify fishing grounds and estimate the fishing intensity on those grounds. 
Neither AIS nor VMS data contain information on the type of fishing activity. Instead, gear type and métier identification for each fishing trip are determined by matching positions to logbook data using date and vessel identifier (Hintzen et al., 2012; Jennings and Lee, 2012; Russo et al., 2011). Logbook records describe daily catch weight by species, gear type employed and effort (hours fished). Catch locations are recorded in ICES statistical rectangles consisting of a grid of $0.5^{\circ}$ latitude by $1^{\circ}$ longitude (Gerritsen and Lordan, 2011). In the EU, gear types can also be identified from the European Union Fleet Register data.

Because position records are not explicitly associated with a specific activity pattern, the use of VMS or AIS data to identify fishing grounds and intensity depends on the ability to distinguish between fishing and non-fishing activities (e.g. steaming vs. stationary). Vessel speed is generally used to determine the fishing action (Campbell et al., 2014; Mills et al., 2007). These methods, which rely on expert knowledge, consist of filtering ships positions using either a predetermined speed threshold or a speed that falls between an upper and lower bound. A review of related work using predetermined speed threshold is presented in Lee et al. (2010) for all types of fishing gear. Filtering is conducted based on the instantaneous ship speed contained in the raw data or from the average ship speed calculated between two successive positions. Gerritsen and Lordan (2011) showed that, depending on the data transmission frequency, the instantaneous speed and the calculated speed can differ greatly. Other methods rely on multivariate analysis of speed, deviation angle, trajectory tortuosity (Mills et al., 2007; Enguehard et al., 2013) or on data mining and machine learning approaches (Gloaguen et al., 2015; Joo et al., 2013) to improve fishing position detection. Gloaguen et al. (2016) found that speed through water was more constant than speed over ground generally used in these algorithms, though it did not improve the capacity of the classification algorithm to correctly detect fishing events.

According to Russo et al. (2013), the term "fishing ground" is widely used in the literature, but no precise and commonly accepted definition exists for identifying these entities. As stated in Jennings and Lee (2012), because the term can have important consequences, the criteria used to define a fishing ground must be explicit, especially in the context of maritime spatial planning. In numerous studies, fishing grounds are defined as the maximum extent containing the VMS positions of fishing vessels (Hintzen et al., 2012; Lee et al., 2010). In contrast, Jennings and Lee (2012) suggested an alternative definition for fishing grounds as those areas in which dense fishing activities occur while Russo et al. (2013) suggested fishing grounds could also be defined as areas with the highest catches or areas with higher potential commercial value. In this article, we assumed that fishing grounds correspond to the spatial extent of high density fishing trajectories. Recently, Natale et al. (2015) used utility distributions based on kernel density estimators (Silverman, 1986) placing a decay probability function at each observed location which are then summed up. However, one of the main problems with pointbased kernel density estimators is that they rarely consider the temporal dimension and sequentiality of points in a trajectory (Demšar et al., 2015). Alternatively, sequentiality of measurement points is taken into account in line-segment kernels in two dimensions (geographic space) (e.g. Downs, 2010; Long and Nelson, 2012) or three dimensions (space-time cube) (Demšar et al., 2014).

This research focused on semi-automatic AIS data processing to estimate the spatial distribution and intensity of dredging métiers with high spatial resolution. In response to a request made by local fishermen, an experiment was conducted in the Bay of Brest. Located on the westernmost tip of Brittany (France) (Fig. 1), the Bay of Brest is a maritime basin of approximately $180 \mathrm{~km}^{2}$ where diverse human maritime activities occur (Gourmelon et al., 2014), among which are commercial fishing dredgers. This fleet, composed of approximately 60 vessels, targets four main species: the great scallop (Pecten maximus), the warty venus (Venus verrucosa), the variegated scallop (Mimachlamys varia) and the flat oyster (Ostrea edulis). Since 1984, commercial bivalve mollusk resources in the bay of Brest are managed through specific spatial and temporal regulations in conjunction with a juvenile stocking programme managed by the Tinduff hatchery in cooperation with the local fishermen committee. Moreover, fishing vessels must own an annual fishing license for bivalve mollusks and must be equipped with an AIS transponder. This context provided a rare opportunity to study the potential of AIS data analysis as a proxy for fishing ground identification at the métier level (i.e., the association of a fishing gear type with a target species) for small vessels $(<15 \mathrm{~m})$. In addition to resource management and optimization issues, knowledge of the spatial and temporal distribution of dredging activities is essential because of their potential impact on marine habitats of community interest (Directive 92/43/EEC) such as maerl beds. Therefore our objective is to explore the feasibility of providing information on the spatio-temporal intra-annual fishing variability for dredge métiers from AIS data in the Bay of Brest.

\section{Material and methods}

\subsection{Data}

Five complementary data sets were used in this study: raw AIS positions, commercial landings, fish auction prices and regulatory data concerning the fishery opening dates and times (fishery calendar) and the identity of licensed fishing vessels (Table S1).

Raw AIS positions were available for 2011-2012, but only from the AIS receiver located in Plouzané restricting the AIS spatial coverage to the western part of the Bay of Brest (Fig. 1). This spatial data limitation precluded identifying the fishing grounds for the warty venus, for which dredging occurs in the eastern part of the bay. However, the spatial coverage encompassed the great scallop fishing grounds.

AIS data contained dynamic information (ship position, course, speed and heading at each time stamp), static information (a unique ship identification number - the Maritime Mobile Service Identity (MMSI) — name, length, width) and voyage-related information (ship status, estimated time of arrival, etc.). The AIS positional data included all ship categories (cargo ships, tankers, passengers vessels, fishing vessels, etc.). Before use AIS positional data were filtered. AIS positions located on land were removed (spatial filter), and only AIS positions corresponding to fishing vessels with a valid fishing licence for dredge gear operations in the Bay of 


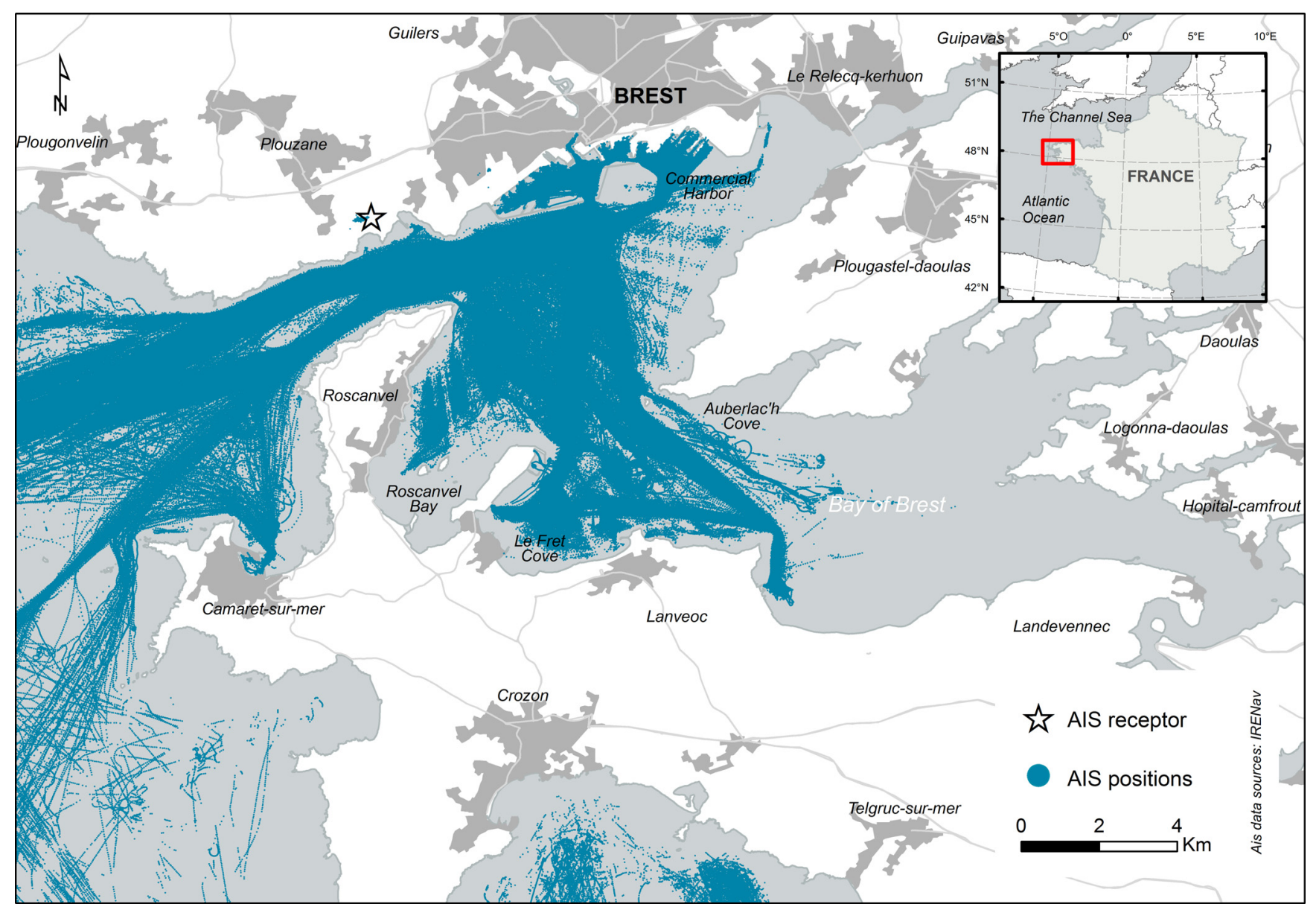

Fig. 1. AIS data coverage used in the case study. Data were collected between October 2011 and March 2012 and provided by the Naval Academy Research Institute.

Brest (qualitative filter) during authorized fishing periods (temporal filter) were retained.

The landing data set described the daily weights of nominal landings (in $\mathrm{kg}$ ) of the four target species (great scallop, warty venus, variegated scallop and flat oyster), for each ship for the 2011-2012 season. The auction price dataset contained daily auction prices (in $€ / \mathrm{kg}$ ) for each species during the same period.

The fishing calendar provided dates and hours when dredge fishing in the Bay of Brest was authorised, while the vessel data set provided the names of ships with a valid dredging licence during the study period.

To validate the method complementary data gathering by onboard observers was carried out (validation data). The observers collected GPS positions during two fishing trips that occurred on 11-03-2015: one for warty venus dredging and the other for variegated scallop dredging. Great scallop dredging has been prohibited since 2014 due to persistent blooms of Pseudo-nitzschia, which causes amnesic shellfish poisoning (ASP); therefore, observation data for this métier were not collected. During these fishing trips, two discrete action modes were noted by the observers: "fishing" and "not fishing". To standardise observations, fishing behaviour was defined as dredges being underwater. The starting and ending times were reported for each fishing behaviour. GPS positions were registered at irregular time steps. In total, 1408 GPS positions were collected during warty venus dredging and 1,041 GPS positions were collected during variegated scallop dredging (Table S2).

\subsection{Method}

The three steps of the approach aimed to: (i) identify and assign métiers for each fishing trip on a daily basis; (ii) differentiate between fishing and non-fishing activities; and (iii) identify fishing grounds and estimate local fishing intensities.

These steps followed the workflow shown in Figure S1. The five data sets were stored in a Postgres Postgis database. Analyses were conducted with R software (R Core Team, 2016).

\subsubsection{Métier identification}

The métier identification was based on daily landings reported for each vessel. Daily landings with a single species represented more than $80 \%$ of the total landings (Figure S2). In this case, the daily métier can be easily identified through the combination of dredge gear and the identity of the landed species. 
For multi-species landings, daily métiers for each fishing trip were identified using Agglomerative Hierarchical Clustering (AHC) (Ward, 1963). Assuming that fishermen aim to maximize revenue rather than landing volume, species composition was expressed in value. Due to large variations of auction prices during a fishing season (Figure S3), daily auction prices were used for this instead of mean prices. The percentage in value $\left(P_{i, j, k}\right)$ for vessel $i(i=1, \ldots, 61)$ of species $j$ $(j=1, \ldots, 4)$ on day $k$ of the fishing season $(k=1, \ldots, 84)$ was derived from landings in weight $\left(W_{i, j, k}\right)$ and auction price $\left(A_{j, k}\right)$ :

$$
P_{i, j, k}=\frac{W_{i, j, k} \times A_{j, k}}{\sum_{j=1}^{n} W_{i, j, k} \times A_{j, k}} \times 100 .
$$

The dissimilarity matrix between daily landings percentages was calculated using the Euclidean distance between $P_{i, j, k}$. The AHC analysis was conducted with the Ward2 algorithm (Murtagh and Legendre, 2014). The number of clusters was automatically selected to explain up to a predefined threshold of the total inertia $(95 \%$ of the total inertia for this study). The mean value of $P_{i, j, k}$ (value $\bar{p}_{i, j, k}$ ) was then calculated for each cluster. To select unambiguous clusters (clusters containing a clear representation of a target species), we only retained clusters where $\bar{P}_{i, j, k}>80 \%$ (this threshold was set a priori). The identified daily métier was linked to AIS positions using vessel MMSI and date.

\subsubsection{Fishing activity identification}

Fishing positions were identified based on vessel speed. Previous analyses of trips with on-board observers (Mills et al., 2007) showed that the speed density profile for trawlers consists of a multi-modal distribution that corresponds to discrete behavioural states. The speed density profile can be decomposed into three modes (low-speed peak, medium-speed peak and high-speed peak) corresponding, respectively, to near-stationary or embarking behaviour, fishing behaviour and steaming behaviour (Bastardie et al., 2010). Assuming that the relationship between vessel speed and behaviour (fishing/ steaming) is similar for dredgers and bottom trawlers, the upper and lower speed bounds likely to correspond to fishing activities were estimated for each métier using automatic hierarchical clustering based on mixture models (Fraley and Raftery, 2002). This method was selected because, in contrast to Natale et al. (2015), no assumption was needed concerning the model and number of components that best fitted the data. The speed profile decomposition was performed using the Mclust package (Fraley et al., 2012). First, the function parameters were automatically selected: the best model was identified maximising the Bayesian Information Criterion (BIC) (Schwarz, 1978) while the number of components was selected based on maximising the Normalized Difference in Entropy (NDE) index (Baudry et al., 2010). Second, these parameters were used to decompose the speed profile with an Expectation-Maximisation (EM) algorithm initialised by hierarchical clustering for parameterised mixture models. Third, the resulting mixture model was plotted together with the speed profile to identify the cluster that best fitted the medium-speed peak values. Finally, using the lower and upper fishing speed bounds for each métier the AIS positions were assigned using a supplementary variable notated as "fishing" and coded as Boolean attributes (0: likely steaming, 1: likely fishing).

\subsubsection{Fishing grounds and intensity estimation}

First, before identifying fishing grounds, the existence of spatial aggregates of fishing positions not resulting from a random distribution was tested using a spatial KolmogorovSmirnov test (referring to a goodness-of-fit test of the uniform distribution) with the R Spatstat package (Baddeley et al., 2015). Second, fishing segments (sub-trajectories) corresponding to at least three time-consecutive fishing positions were computed. To limit the spatial uncertainty, only those segments for which the time interval between two successive AIS positions $\left(t d_{i j}\right)$ was less than $600 \mathrm{~s}$ were retained (max $\left.\left(t d_{i j}\right)<600 \mathrm{~s}\right)$. Third, assuming that fishing grounds corresponded to a higher density of fishing activity, we computed the kernel density of fishing segments for different time windows (daily, monthly, seasonal). Here, the segment Kernel Density Estimation (KDE) was preferable for two main reasons. Because AIS data transmissions are related to vessel speed, a point-based KDE would illustrate the density of AIS transmissions rather than the fishing density distribution. Grid size $(g)$ and the smoothing factor $(h)$ were calculated using non-parametric estimation. The grid size $(g)$ was determined by the 90th percentile of the distance between nearestneighbour AIS positions $(k d=2)$ (Hengl et al., 2008). The smoothing parameter $(h)$ was estimated using the LeastSquare Cross-Validation algorithm which minimizes the Mean Integrated Square Error (Calenge et al., 2009; Calenge, 2006). Delimitation of the fishing grounds was performed by extracting the 95th percentile of the Kernel density. This threshold is usually used to define the home range of mobile animals (Powell, 2000). To avoid unrepresentative fishing grounds and limit artefact, fishing areas $\left(S_{a}\right)$ smaller than $1.5 \times 10^{-2} \mathrm{~km}^{2}$ (approximately a $125-\mathrm{m}$ square) were not considered. Finally, we assessed fishing intensity expressed as the total time spent fishing (in hours) per unit area (in square kilometres) per unit time (a dredging season) (Lee et al., 2010) with the trip package (Sumner, 2015). Global raster data analysis was performed with the raster package (Hijmans et al., 2015).

\subsection{Performance evaluation}

The performance of the method, i.e. its ability to differentiate between fishing and non-fishing activities and propagate errors from the identification of fishing grounds to estimates of fishing intensity, was evaluated against the known fishing positions in the validation data set.

The comparison of known (i.e., observed) fishing positions to the estimated fishing positions was performed using a confusion matrix. The overall accuracy $(A)$ and the Kappa index $(K)$ were calculated to evaluate the classification accuracy (Kuhn, 2008).

Fishing grounds and fishing intensities were computed from known fishing positions and with estimated fishing positions. The results were compared using the $I$ similarity 


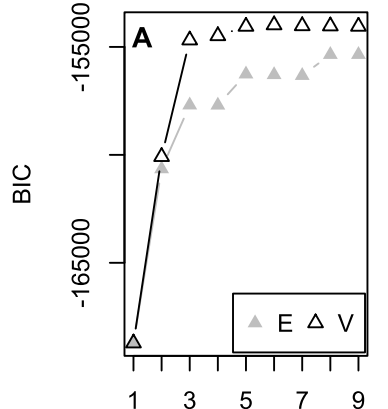

Number of components

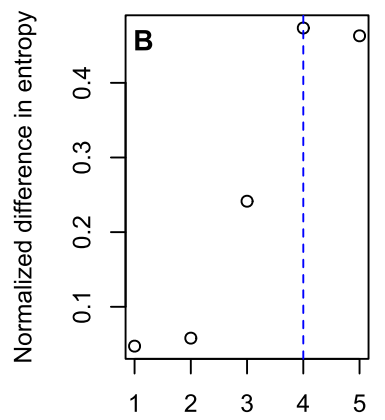

Number of components
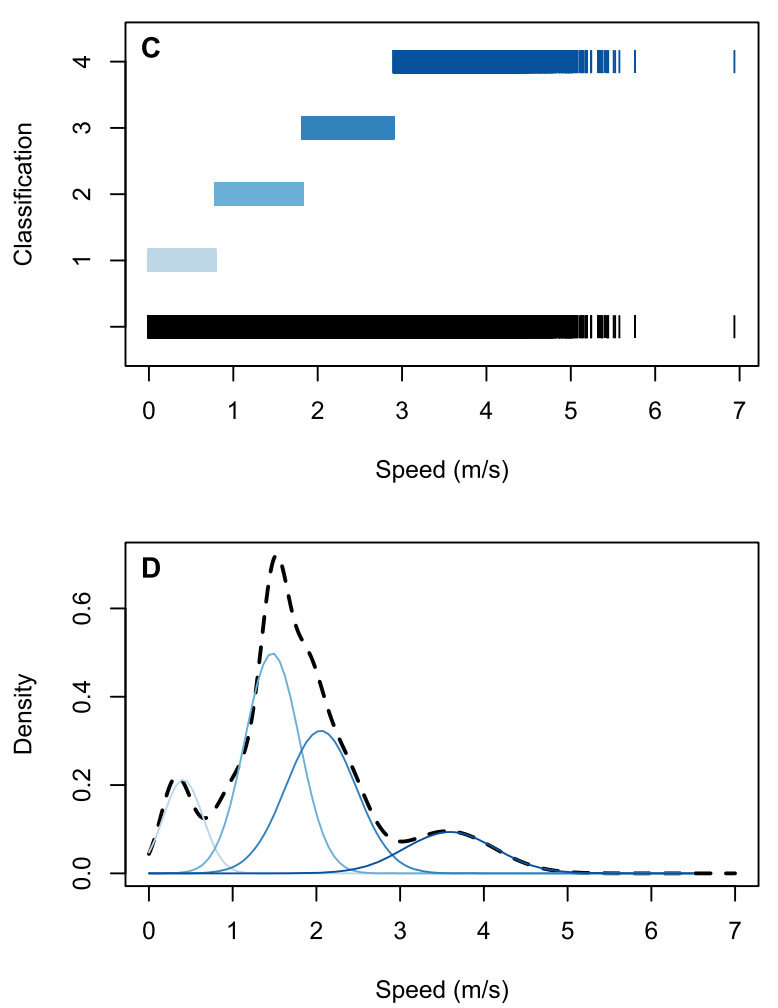

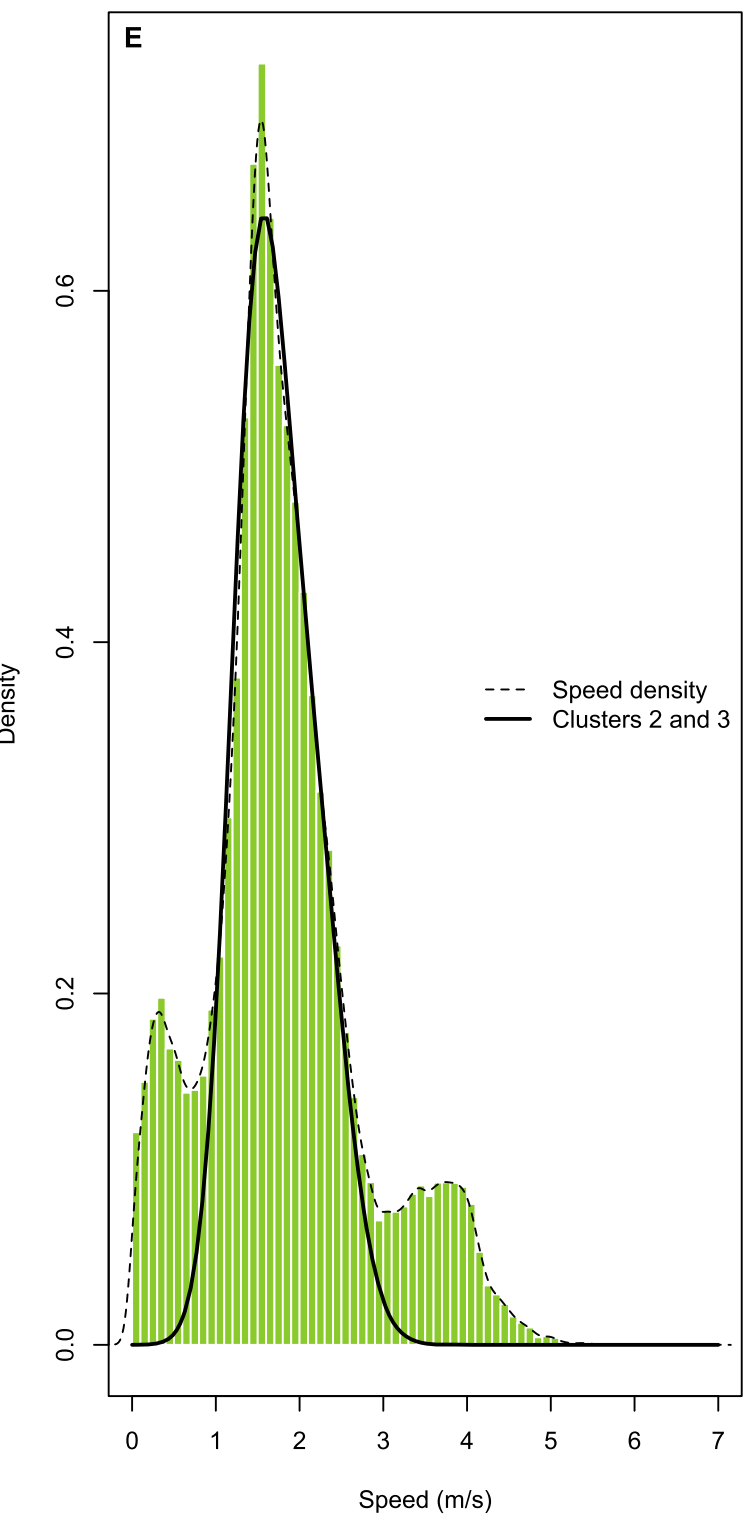

Fig. 2. Density estimation and classification via a finite mixture model for the great scallop dredging speed profile. Mclust parameter selection for (A) the optimum model (E: one-dimensional equal variance, V: one-dimensional variable variance) and for (B) the optimum number of components. Mclust results with (C) the speed range distribution for each identified cluster, (D) the mixture model for the speed profile, and (E) the density profile corresponding to the second peak of speed values.

statistic (Warren et al., 2008; VanDerWal et al., 2014). This global metric sums the pairwise differences between two predictions to create a single value representing the similarity of the two distributions (i.e., based on the spatial distribution and intensity of a variable). The $I$ similarity statistic ranges from 0 , where the two distributions have no overlap, to 1 , where the two distributions are identical.

\section{Results}

\subsection{Métiers}

The AHC carried out on daily species compositions of vessel landings in value $\left(P_{i, j, k}\right)$ identified six clusters of which three were dominated by a single species (Figure S4). The three clusters dominated by a single species corresponded to the métiers great scallop dredging, Warty venus dredging and variegated scallop dredging. Vessel-days assigned to the three mixed species clusters were assigned to "other métiers" and not considered further. The majority of considered vesseldays $(75 \%, 1,875$ vessel-days) were assigned to the great scallop dredging métier. Warty venus dredging contained $20 \%(821)$ of vessel-days and variegated scallop dredging $5 \%$ (161) of vessel-days (Table S3). The Warty venus dredging métier contained the largest number of vessel-days for which the other two species contributed value to landings ( $74 \%$ of vessel-days assigned to this métier), whereas only around $13 \%$ of vessel days assigned to the great scallop and variegated scallop dredging métiers had landings from the other two species. 


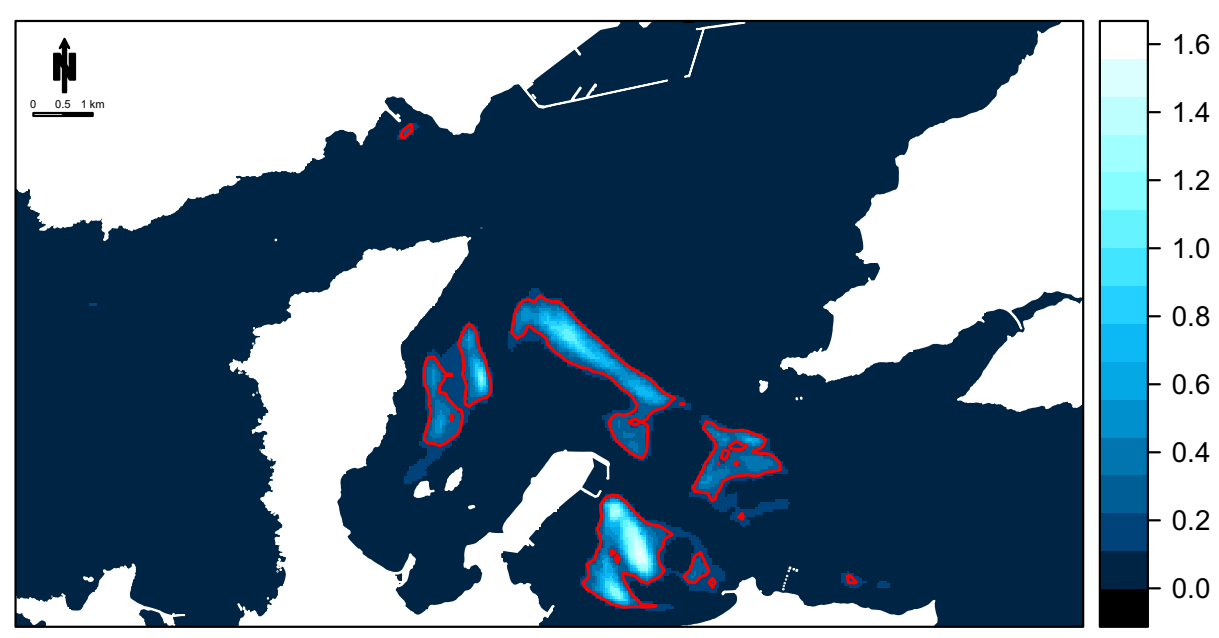

Fig. 3. Spatial distribution of yearly kernel density of fishing segments for great scallop dredging during 2011-2012. The red lines highlight the 95th percentile.

Table 1. Descriptive statistics for each fishing zone for great scallop dredging in the western Bay of Brest identified from AIS data.

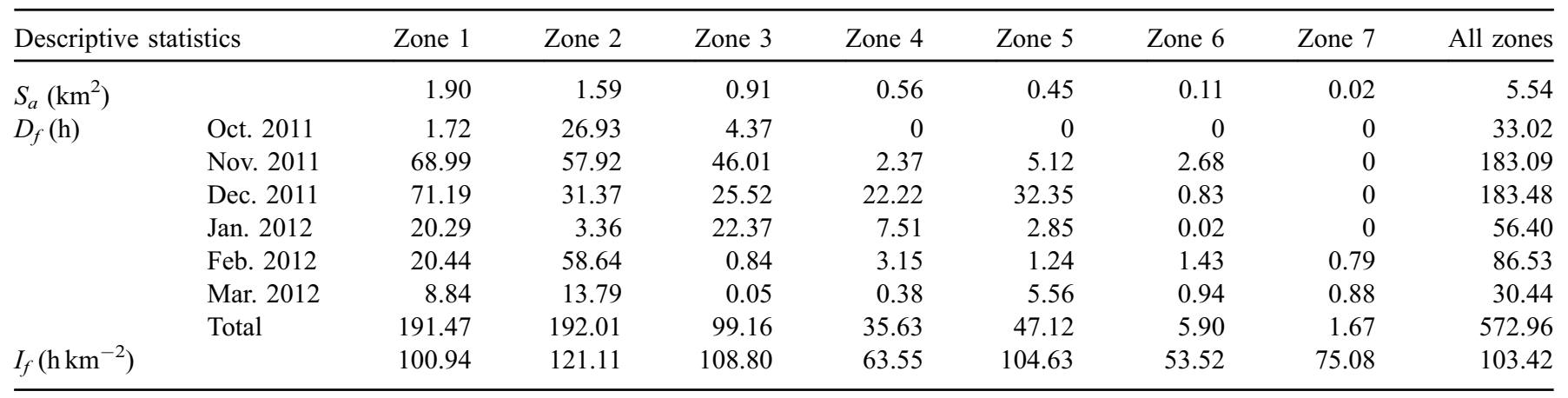

Surface area $\left(S_{a}\right)$ in square kilometres $\left(\mathrm{km}^{2}\right)$, fishing duration $\left(D_{f}\right)$ in hours $(\mathrm{h})$ and fishing intensity $\left(I_{f}\right)$ in hours per square kilometre $\left(\mathrm{h}\right.$ km $\left.{ }^{-2}\right)$.

Linking identified daily métiers and AIS positions resulted in 81,273 positions for great scallop, 2,394 for warty venus and 21 for variegated scallop dredging. Almost all AIS positions (97\%) corresponded to great scallop dredging. This result is due to the limited spatial coverage of the raw AIS database as explained above.

\subsection{Fishing activity}

Density estimation and classification for great scallop dredging speed profiles using a finite mixture model are shown in Figure 2. Using the BIC criterion a mixture model with unequal variances between components densities was selected (Fig. 2A). The speed density profile comprised 4 components according to the NDE index (Fig. 2B). The results of the speed profile decomposition identified the first cluster as $0-0.79 \mathrm{~m} \mathrm{~s}^{-1}$, the second cluster as $0.80-1.82 \mathrm{~m} \mathrm{~s}^{-1}$, the third cluster as $1.83-2.90 \mathrm{~m} \mathrm{~s}^{-1}$ and the fourth as $2.91-6.09 \mathrm{~m} \mathrm{~s}^{-1}$ (Fig. 2C). Plotting the selected mixture model and the speed profile together (Fig. 2D) revealed that the second peak in the density of speed values which is likely to correspond to dredging was part of the second and third cluster (Fig. 2D and Fig. 2E). The lower and upper bounds of fishing speed for great scallops dredging were therefore 0.8 and $2.9 \mathrm{~m} \mathrm{~s}^{-1}$, respectively. Based on this speed range, 50,820 AIS positions $(62.5 \%$ of the total positions for great scallops dredging) were classified as likely fishing positions.

\subsection{Fishing grounds and intensity}

The observed distribution of AIS positions for the great scallops dredging differed significantly from a uniform distribution (two-sided spatial Kolmogorov-Smirnov test of Complete Spatial Randomness in two dimensions, $D=0.274$, $p<.001)$. The input parameters for the kernel density of fishing segments were estimated as $g=25 \mathrm{~m}$ and $h=47 \mathrm{~m}$.

Ten great scallop dredging fishing grounds were identified in the study area based on the 95th percentile of the kernel density of fishing segments for the 2011-2012 season (Fig. 3). Among the ten fishing grounds, seven fullfilled the minimum area criteria $\left(A>1.5 \times 10^{-2} \mathrm{~km}^{2}\right)$. The seven fishing areas were numbered by decreasing surface area (Tab. 1). Zone 1 lies in the centre of the Bay of Brest, zone 2 in the south, in Le Fret cove, zone 3 in the east, near Auberla'ch cove, zone 4 in the middle-western part of the bay, zone 5 in the middle-western portion of the bay between zone 4 and zone 1, zone 6 in the 

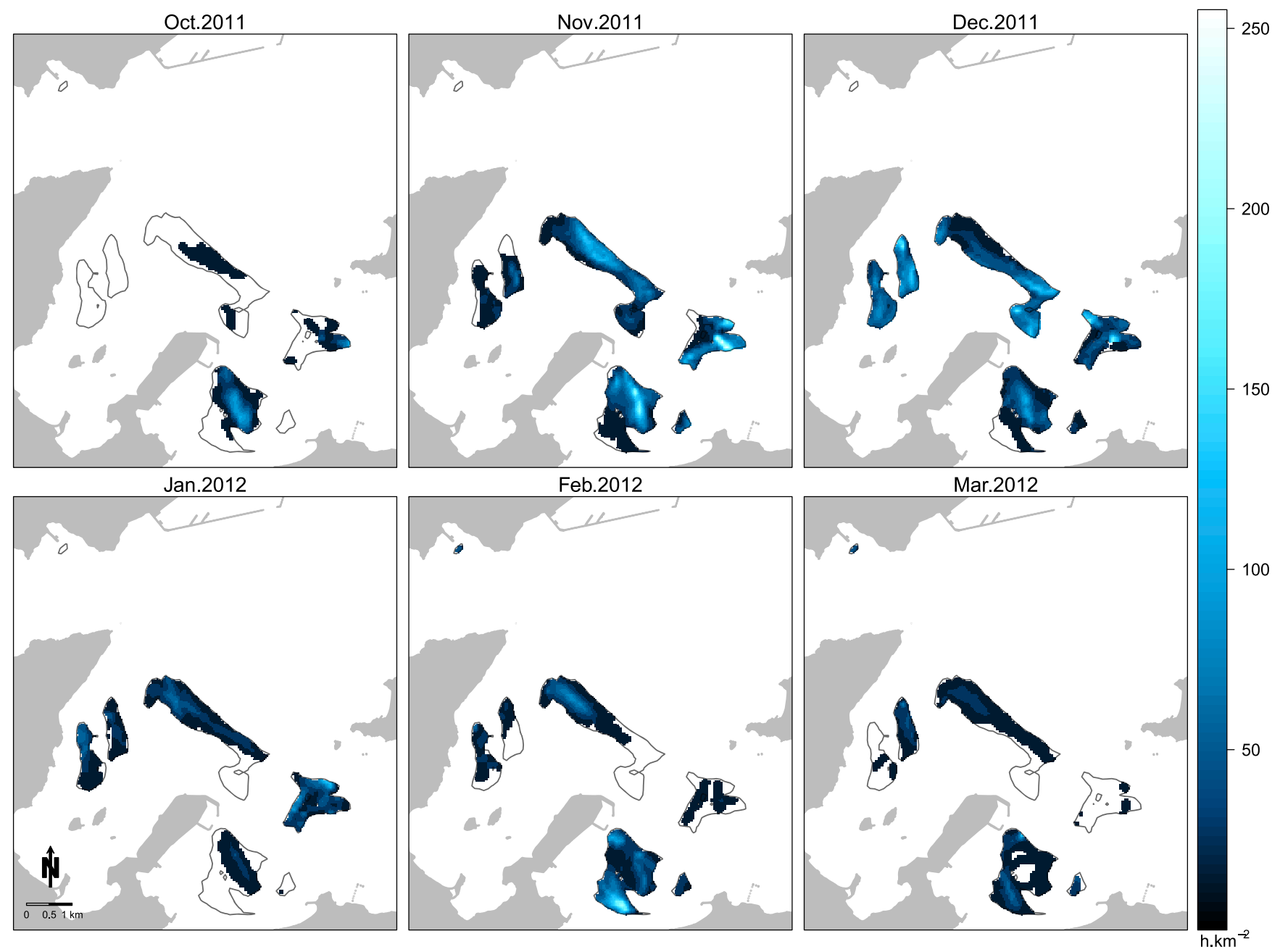

Fig. 4. Monthly fishing intensity of great scallop dredging for 2011-2012. Fishing intensity is expressed in hours per square kilometres $\left(\mathrm{h} \mathrm{km}^{-2}\right)$.

southeast, lastly, zone 7 in the northwest. Total fishing duration was estimated at $573 \mathrm{~h}$ for all fishing zones (Tab. 1). Great scallop dredging was mainly concentrated in zones 1 and 2 $(192 \mathrm{~h})$. Zone 3 represented about half of this duration with $99.1 \mathrm{~h}$, and finally zones 5, 4, 6 and 7 with, respectively, $47.1 \mathrm{~h}$, $35.6 \mathrm{~h}, 5.9 \mathrm{~h}$ and $1.6 \mathrm{~h}$.

The spatial pattern of fishing intensity varied between October 2011 and March 2012 (Tab. 1, Fig. 4). Most fishing took place during November and December 2011 (183 h each), representing $64 \%$ of the total duration. Overall fishing intensity ranged from $121.1 \mathrm{~h} \mathrm{~km}^{-2}$ for zone $2-53.5 \mathrm{~h} \mathrm{~km}^{-2}$ for zone 6 $\left(\tilde{I_{f}}=100.9\right)$.

\subsection{Evaluation}

The overall classification accuracy for the validation data set was $91 \%(K=0.80)$ for vessels dredging for warty venus and $87 \%(K=0.73)$ for vessels dredging variegated scallops (Table S4 and Figure S5). The misclassification rate was similar for the two métiers for steaming positions $(5 \%$ and $3 \%$ ), but higher for fishing positions for variegated venus dredgers $(10 \%)$ compared to warty venus dredgers $(4 \%)$.
However, these errors in fishing detection propagated little to errors in fishing ground identification and fishing intensity estimation. The estimated spatial distributions for both descriptors were close to the observed distributions according to Warren's similarity index $\left(I_{W v}=0.95, I_{V s}=0.94\right.$ for fishing grounds and $I_{W v}=0.96, I_{V s}=0.92$ for fishing intensity).

\section{Discussion}

This study explored the feasibility of providing information on dredge fishing at a fine spatial scale using AIS data. To our knowledge, no previous study has used AIS data to assess the spatio-temporal distribution and intensity of fishing at the métier level. The fine resolution of fishing characterization achieved here is needed by local managers for resource management and conservation.

The study identified seven fishing zones where great scallop dredging in the Bay of Brest was concentrated during the 2011-2012 season. The estimated overall fishing duration was $573 \mathrm{~h}$, mostly concentrated in two zones. During the first months of fishing (October to December, 2011), fishing intensity was mainly concentrated in the southern part of the 
area, which had been stocked with juveniles in the previous year. We speculate that fishermen prioritized this area because they expected it would contain a higher density of great scallops. We believe this result should be of interest to the fishermen commission for shellfish resources management to explain the Tinduff hatchery's activity (and hence the cost of fishing licences regularly questioned by fishermen), and for the strategy for stocking juvenile shellfish.

The study demonstrated the feasibility of monitoring dredge fishing intensity using AIS data in the Bay of Brest. Restriction scallops dredging due to excessive ASP toxin levels since 2014 would have resulted in increased fishing effort targeting the warty venus. This bivalve lives buried in coarse sediments including maërl beds. Such monitoring could evaluate to what extent the dredging effort has been shifted towards the warty venus, as the AIS spatial coverage has been improved in 2013 with a second AIS receptor now being located in the south of the Bay. The availability of quantitative fishing pressure estimates contributes to current research efforts aiming at estimating the potential impact of those fishing gears on coastal benthic habitats such as maërl beds in the Bay of Brest and elsewhere. Such indicators are also required for monitoring the ecological status of coastal habitats to comply with the UE Marine Strategy Framework Directive (MSFD) and the Habitats Directive (Directive 92/43/EEC) requirements.

The results of this study are promising but the application of the method depends on certain conditions and has a number of limitations. First, acceptance for providing landings data (i. e., personal data) is required; this data is needed to identify fishing métiers. Acceptance of onboard observers for complementary data collection depends on a strong collaboration with fishermen and their representatives. Second, availability of AIS data is a prerequisite for the analysis. In this study, the spatial coverage of the AIS data was limiting. Only AIS messages transmitted by vessels located in the western part of the Bay of Brest were collected by the single available AIS receiver. Consequently, we were only able to identify fishing grounds for one métier (great scallop dredging). Further, the analysis was conducted only for one fishing season, which does not allow any generalizations. Third, the limitations inherent to the nature of AIS data need to be considered. Indeed, although the AIS regulation is certainly clear for the dredge fleet (vessels under 12 metres) in the Bay of Brest, not all fishing vessels have to carry an AIS system under EU regulations. AIS data can also be incomplete (Robards et al., 2016) or be falsified, and AIS transmissions can be shut down. Because the raw AIS data also include personal information, analysis and results must guarantee a sufficient degree of anonymity.

The accuracy of fishing ground identification depends on the ability to differentiate between fishing and non-fishing behaviours. In this study a simple classification of positions based on speed was used. The evaluation of the accuracy of this method of differentiation was estimated based on two complementary datasets (two trips) for the two métiers warty venus and variegated scallop dredging and cannot be considered as representative regarding the whole dredge fleet in the Bay of Brest (60 ships).

Data collection is time consuming and the number of sampled observations should — in theory — be sufficient to perform statistical comparisons. For this reason, the total number of trips used for comparison should certainly be increased in future studies. The difference in the median time interval between AIS positions ( 30 seconds) compared to those of the GPS positions (15 seconds) used for evaluating the method might have influenced our results. Evaluation of the method should be carried out with AIS data labelled from observations or with GPS data re-sampled to comply with the AIS median time interval. One disadvantage of the proposed method is its parametric selection of speed clusters corresponding to the medium peak of the speed density. Further work might consider an automatic alternative and evaluate whether the ability to differentiate between fishing and nonfishing behaviours could be improved using methods from the field of behavioural ecology (multivariate approaches) or machine learning (Vermard et al., 2010; de Souza et al., 2016).

Fishing ground identification relied on kernel density estimation that considers the sequentiality of fishing positions in a trajectory. A possible next step is to consider whether fishing ground estimation could be improved through Utilization Distribution (UD) with Brownian Bridge Movement Models that assume random movement between positions (Buchin et al., 2012) or with 3D line-segment kernels that explicitly consider the temporal dimension in trajectories (Demšar et al., 2014).

Notwithstanding the caveats listed above, we believe that the proposed approach is complementary (Russo et al., 2016) to other sources of information such as VMS data or participatory mapping (Kafas et al., 2017). In cases where data are scarce, the proposed method provides a potential solution for small-scale fisheries to estimate fishing grounds and fishing intensities at high resolution. The method was developed using free and open source software and is intended for dissemination within an $\mathrm{R}$ package. Further work might include data analysis over several years and with better spatial coverage to estimate the inter-annual variability of fishing grounds. This would also enable allocating dredging to spatial catches (landings), spatial effort (via fishing vessel characteristics from the European fleet registry) and seabed pressure (spatial effort linked to the size of the gear towed) (Eigaard et al., 2016). By adding additional layers of fishing intensity compliant with local scales, trade-offs could be evaluated between socio-economic and conservation objectives using spatial optimization tools such as Marxan (Watts et al., 2009).

\section{Supplementary material}

The following supplementary material is available: Table S1 provides main characteristics of the datasets including AIS positions, landings, auction prices, fishing calendars and ships, Table S2 shows the descriptive summary of GPS data collection, Table S3 shows the classification of landings by dredge métiers, related AIS positions and daily fishing trips available in the raw AIS database, Table S4 shows the summary statistics concerning the evaluation of the method, Figure S1 shows the graphical overview of the three main steps involved in data preprocessing and analysis, Figure S2 shows the proportions of the weights of landings per boat and per species, Figure S3 shows the density and variations in auction prices during the 2011-2012 season for the target 
species, Figure S4 shows the results of the AHC carried out on $P_{B_{i}, S_{i}, D_{k}}$ values and Figure S5 presents the spatial distributions of the observed and the estimated descriptors (states, fishing grounds and fishing intensity) for the variegated scallop dredging trip.

The Supplementary Material is available at http://www.alrjournal.org/10.1051/alr/2017038/olm.

Acknowledgments. This study was funded by the Fondation de France through the programme "Coasts for tomorrow". It also benefited from a state subsidy managed by the Agence Nationale de la Recherche (ANR, National Agency for Research) within the framework of the "Investments for the Future" program, reference ANR-10-LABX-19-01. We would like to thank the local fishermen committee for their willingness to share knowledge and the Naval Academy Research Institute for providing the AIS database. We thank the editor and the anonymous reviewers for their constructive comments, which helped us to improve the manuscript.

\section{References}

Baddeley A, Rubak E, Turner R. 2015. Spatial point patterns: methodology and applications with R. Chapman and Hall/CRC Press, London.

Bastardie F, Nielsen JR, Ulrich C, Egekvist J, Degel H. 2010. Detailed mapping of fishing effort and landings by coupling fishing logbooks with satellite-recorded vessel geo-location. Fish Res 106: 41-53.

Baudry JP, Raftery AE, Celeux G, Lo K, Gottardo R. 2010. Combining mixture components for clustering. J Comput Graph Stat 19: 332-353.

Boulcott P, Millar CP, Fryer RJ. 2014. Impact of scallop dredging on benthic epifauna in a mixed-substrate habitat. ICES J Mar Sci 71: 834-844.

Breen P, Vanstaen K, Clark RWE. 2015. Mapping inshore fishing activity using aerial, land, and vessel-based sighting information. ICES J Mar Sci 72: 467-479.

Buchin K, Arseneau T, Sijben S, Willems EP. 2012. Detecting movement patterns using Brownian bridges, in: Proceedings of the 20th International Conference on Advances in Geographic Information Systems, pp. 119-128.

Calenge C. 2006. The package "adehabitat" for the R software: A tool for the analysis of space and habitat use by animals. Ecol Model 197: 516-519.

Calenge C, Dray S, Royer-Carenzi M. 2009 The concept of animals' trajectories from a data analysis perspective. Ecol Inform 4: 3441.

Campbell MS, Stehfest KM, Votier SC, Hall-Spencer JM. 2014. Mapping fisheries for marine spatial planning: gear-specific vessel monitoring system (VMS), marine conservation and offshore renewable energy. Mar Policy 45: 293-300.

Demšar U, Buchin K, Cagnacci F, Safi K,Speckmann B, de Weghe NV, Weiskopf D, Weibel R. 2015. Analysis and visualisation of movement: an interdisciplinary review. Mov Ecol 3: 5.

Demšar U, Buchin K, van Loon EE, Shamoun-Baranes J. 2014. Stacked space-time densities: a geovisualisation approach to explore dynamics of space use over time. GeoInform 19: 85-115.

Downs JA 2010. Time-geographic density estimation for moving point objects, Springer Berlin Heidelberg, Berlin, Heidelberg, 16-26.

Dunn DC, Maxwell SM, Boustany AM, Halpin PN. 2016 Dynamic ocean management increases the efficiency and efficacy of fisheries management. Proceedings of the National Academy of Sciences 113: 668-673.

EC. 2002. Council Regulation EC No. 2371/2002 of 20 December 2002 on the conservation and sustainable exploitation of fisheries resources under the Common Fisheries Policy. Off J: 59-80.

Eigaard OR, Bastardie F, Breen M, Dinesen GE, Hintzen NT, Laffargue P, Mortensen LO, Nielsen JR, Nilsson HC, O’Neill FG, Polet H, Reid DG, Sala A, Sköld M, Smith C, SØrensen TK, Tully O, Zengin M, Rijnsdorp AD. 2016. Estimating seabed pressure from demersal trawls, seines, and dredges based on gear design and dimensions. ICES J Mar Sci 73: i27-i43.

Enguehard RA, Hoeber O, Devillers R. 2013. Interactive exploration of movement data: a case study of geovisual analytics for fishing vessel analysis. Inf Vis 12: 65-84.

Fraley C, Raftery AE. 2002. Model-based clustering, discriminant analysis, and density estimation. J Am Stat Assoc 97: 611-631.

Fraley C, Raftery AE, Murphy TB, Scrucca L. 2012. Mclust version 4 for R: normal mixture modeling for model-based clustering, classification, and density estimation, Technical report 597, Department of Statistics, University of Washington.

Gerritsen H, Lordan C. 2011. Integrating vessel monitoring systems (VMS) data with daily catch data from logbooks to explore the spatial distribution of catch andeffort at high resolution. ICES J. Mar Sci 68: 245-252.

Gloaguen P, Mahévas S, Rivot E, Woillez M, Guitton J, Vermard Y, Etienne MP. 2015. An autoregressive model to describe fishing vessel movement and activity. Environmetrics 26: 17-28.

Gloaguen P, Woillez M, Mahévas S, Vermard Y, Rivot, E. 2016. Is speed through water a better proxy for fishing activities than speed over ground? Aquat Living Resour 29: 210.

Gourmelon F, Le Guyader D, Fontenelle G. 2014. A dynamic GIS as an efficient tool for integrated coastal zone management. ISPRS Int J Geo-Inf 3: 391-407.

Hengl T, van Loon E, Shamoun-Baranes J, Bouten W. 2008. Geostatistical analysis of GPS trajectory data: space-time densities, in: Proceedings of the 8th International Symposium on Spatial Accuracy Assessment in Natural Resources and Environmental Sciences, World Academic Press, Shanghai, China, pp. 17-24.

Hijmans RJ, van Etten J, Mattiuzzi M, Sumner M, Greenberg JA, Lamigueiro OP, Bevan A, Racine EB, Shortridge A. 2015 Raster: Geographic data analysis and modeling..

Hintzen NT, Bastardie F, Beare D, Piet GJ, Ulrich C, Deporte N, Egekvist J, Degel H. 2012. VMS tools: Open-source software for the processing, analysis and visualisation of fisheries logbook and VMS data. Fish Res 115-116: 31-43.

Hinz H, Murray LG, Lambert GI, Hiddink JG, Kaiser MJ. 2013. Confidentiality over fishing effort data threatens science and management progress. Fish Fish 14: 110-117.

HØye GK, Eriksen T, Meland BJ, Narheim BT. 2008. Space-based AIS for global maritime traffic monitoring. Acta Astronaut 62: 240-245.

Jennings S, Lee J. 2012. Defining fishing grounds with vessel monitoring system data. ICES J. Mar Sci 69: 51-63.

Joo R, Bertrand S, Tam J, Fablet R. 2013. Hidden Markov models: the best models for forager movements? PLoS ONE 8: e71246.

Kafas A, McLay A, Chimienti M, Scott BE, Davies I, Gubbins M. 2017. ScotMap: participatory mapping of inshore fishing activity to inform marine spatial planning in Scotland. Mar Policy 79: 8-18.

Kuhn M. (2008) Building predictive models in $\mathrm{R}$ using the caret package. J Stat Softw 1: 2008.

Lee J, South AB, Jennings S. 2010. Developing reliable, repeatable, and accessible methods to provide high-resolution estimates of fishing-effort distributions from vessel monitoring system (VMS) data. ICES J Mar Sci 67: 1260-1271. 
Long JA, Nelson TA. 2012. Time geography and wildlife home range delineation. J Wildl Manag 76: 407-413.

McCauley DJ, Woods P, Sullivan B, Bergman B, Jablonicky C, Roan A, Hirshfield M, Boerder K, Worm B. 2016. Ending hide and seek at sea. Science 351: 1148-1150.

Mills CM, Townsend SE, Jennings S, Eastwood PD, Houghton CA. 2007. Estimating high resolution trawl fishing effort from satellitebased vessel monitoring system data. ICES J Mar Sci 64: 248-255.

Murtagh F, Legendre P. 2014. Ward's hierarchical agglomerative clustering method: which algorithms implement Ward's criterion? J Classification 31: 274-295.

Natale F, Gibin M, Alessandrini A, Vespe M, Paulrud A. 2015. Mapping fishing effort through AIS data. PLOS ONE 10: e0130746.

Piet GJ, Quirijns FJ, Robinson L, Greenstreet SPR. 2007. Potential pressure indicators for fishing, and their data requirements. ICESJ Mar Sci 64: 110-121.

Powell RA. 2000. Animal home ranges and territories and home range estimators, in: Pearl MC, Boitani L, Fuller TK (Eds.), Research techniques in animal ecology. Columbia University Press. Controversies and Consequences, 2nd edition, pp. 65-110.

R Core Team (2016). R: A Language and Environment for Statistical Computing, R Foundation for Statistical Computing, Vienna, Austria.

Robards M, Silber G, Adams J, Arroyo J, Lorenzini D, Schwehr K, Amos, J, 2016. Conservation science and policy applications of the marine vessel Automatic Identification System (AIS) - a review. Bull Mar Sci 92: 75-103.

Russo T, D'Andrea L, Parisi A, Cataudella S. 2014.. VMSbase: an RPackage for VMS and logbook data management and analysis in fisheries ecology. PLoS ONE 9: e100195.

Russo T, D'Andrea L, Parisi A, Martinelli M, Belardinelli A, Boccoli F, Cignini, I, Tordoni M, Cataudella S. 2016. Assessing the fishing footprint using data integrated from different tracking devices: Issues and opportunities. Ecol Indic 69: 818-827.

Russo T, Parisi A, Cataudella S. 2011. New insights in interpolating fishing tracks from VMS data for different métiers. Fish Res 108: 184-194.
Russo T, Parisi A, Cataudella S. 2013. Spatial indicators of fishing pressure: Preliminary analyses and possible developments. Ecol Indicators 26: 141-153.

Schwarz G, 1978. Estimating the Dimension of a Model. The Ann Stat 6: $461-464$

Shelmerdine RL. 2015. Teasing out the detail: How our understanding of marine AIS data can better inform industries, developments, and planning. Mar Policy 54: 17-25.

Silverman B. 1986. Density estimation for statistics and data analysis, in: Cox D, Hinkley D, Reid N, Rubin D, Silverman B. (Eds.), Monographs on Statistics and Applied Probability. Chapman \& Hall, London, p. 155.

de Souza EN, Boerder K, Matwin S, Worm B. 2016. Improving fishing pattern detection from satellite AIS using data mining and machine learning. PLOS ONE 11: e0158248.

Sumner, MD, 2015. Trip: Tools for the Analysis of Animal Track Data.

Tidd AN, Vermard Y, Marchal P, Pinnegar J, Blanchard JL, MilnerGulland EJ. 2014. Fishing for space: fine-scale multi-sector maritime activities influence fisher location choice. PLOS ONE 10: e0116335.

VanDerWal J, Falconi L, Januchowski S, Shoo L 2014.. Storlie C. SDMTools: Species distribution modelling tools: tools for processing data associated with species distribution modelling exercises. R package version 1.1-221.

Vermard Y, Rivot E, Mahévas S, Marchal P, Gascuel D. 2010. Identifying fishing trip behaviour and estimating fishing effort from VMS data using Bayesian Hidden Markov Models. Ecol Model 221: 1757-1769.

Vespe M, Gibin M, Alessandrini A, Natale F, Mazzarella F, Osio GC. 2016. Mapping EU fishing activities using ship tracking data. $J$ Maps 0: 1-6.

Ward JH. 1963. Hierarchical grouping to optimize an objective function. $J$ Am stat assoc 58: 236-244.

Warren DL, Glor RE, Turelli M. 2008. Environmental niche equivalency versus conservatism: quantitative approaches to niche evolution. Evol 62: 2868-2883.

Watts ME, Ball IR, Stewart RS, Klein CJ, Wilson K, Steinback C, Lourival R, Kircher L, Possingham HP. 2009. Marxan with zones: software for optimal conservation based land- and sea-use zoning. Environ Model Softw 24: 1513-1521.

Cite this article as: Le Guyader D, Ray C, Gourmelon F, Brosset D. 2017. Defining high-resolution dredge fishing grounds with Automatic Identification System (AIS) data. Aquat. Living Resour. 30: 39 